Accepted manuscript: Coen, S. E., Subedi, R. P., \& Rosenberg, M. W. (2016). Working out across Canada: Is there a gender gap? The Canadian Geographer, 60(1), 69-81. https://doi.org/10.1111/cag.12255

\title{
Working out across Canada: Is there a gender gap?
}

SHORT RUNNING TITLE: Working out across Canada

Stephanie E. Coen

Department of Geography, Queen's University

Rajendra P. Subedi

Department of Geography, Queen's University

Mark W. Rosenberg

Department of Geography, Queen's University

Correspondence to/Adresse de correspondance: Stephanie E. Coen, Department of Geography, Queen's University, Mackintosh-Corry Hall, 68 University Avenue, Kingston, Ontario K7L 3N6. Email/Courriel: stephanie.coen@queensu.ca

Globally, boys and men are more physically active than girls and women. Despite geographical variation in physical activity participation and gender differences across types of physical activities, physical activity is frequently assessed at national scales using only select indicators. Using 2012 Canadian Community Health Survey data, we undertake a gender-based analysis using cross tabulations, chi-square tests, and binary logistic regression models to investigate whether gender differences in physical activity vary across geographical scales and physical activity types in Canada. We examine: (1) whether gender gaps in physical activity change across geographical scale (national, provincial, city); (2) if any geographical variation in gender differences varies by activity type (active leisure time, weight-training, home exercises); (3) whether age and/or income help to explain geographical variation in gender differences in physical activity; and (4) if gender, age, marital status, education, and income level predict variation in differences in physical activity at different geographical scales. Results demonstrate that both scale and activity type matter for how gender differences in physical activity are observed. By zooming in or out, or by changing the activity lens, gender gaps emerged or disappeared. We conclude that physical activity interventions need to be gender-sensitive in ways that are place-specific.

Key words: gender, health, scale, physical activity

Key messages

1. We consider how scale and activity type matter for the gender gap in physical activity in Canada.

2. Results show the nature and direction of physical activity gender gaps vary.

3. Interventions need to be gender-sensitive in ways that are place-specific. 


\section{Introduction}

The gender gap in physical activity is global. Around the world, boys and men are more active than girls and women (Ransdell et al. 2004; Hallal et al. 2012). Meeting even minimal physical activity requirements can significantly reduce the risk of coronary heart disease, type 2 diabetes, breast and colon cancers, and premature mortality (Lee et al. 2012). Women, however, being under-represented in the active population, miss out on these benefits compared to their male counterparts.

Canada does not buck this global trend. Canadian men engage in more moderate-tovigorous physical activity (Colley et al. 2011), are more likely to be at least moderately active in their leisure time (Gilmour 2007), and fare better than women in all categories of fitness, except flexibility (Shields et al. 2010). This situation has persisted over time. Analysis of six nationally representative cross-sectional Canadian health surveys from 1994 to 2005 showed that although both men and women made gains in active leisure and transport, they did so in a parallel fashion, leaving the gap between them intact (Juneau and Potvin 2010). There are also important differences in the types of physical activities that Canadian women and men practice in their leisure time (Gilmour 2007). Although gender differences are apparent nationally, physical activity participation is not the same across Canada. Gilmour (2007), using the 2005 Canadian Community Health Survey (CCHS), identified a west-to-east decreasing gradient in leisure time physical activity by province. Canada's largest metropolitan areas also have some of the lowest levels of physical activity, compared to national rates (Gilmour 2007). Geographies of physical activity are clearly inseparable from gendered practices of physical activity in Canada.

We undertake a gender-based analysis using cross tabulations, chi-square tests, and binary logistic regression models to investigate whether gender differences in physical activity vary across geographical scales and physical activity types in Canada. Specifically, we seek to determine: (1) whether gender gaps in physical activity change across geographical scale (national, provincial, city); (2) if any geographical variation in these gender differences varies by activity type (active leisure time, weight-training, home exercises); (3) whether age and/or income help to explain any geographical variation in gender differences in physical activity; and (4) if gender, age, marital status, education, and income level predict variation in differences in physical activity at different geographical scales. In doing so, we aim to contribute a more nuanced understanding of gender, socioeconomic status, and physical activity in the Canadian context. Identifying factors that level the gender playing field for physical activity is critical for developing interventions to increase physical activity participation.

\section{Gendering geographies of physical activity}

A growing interdisciplinary body of gender and health literature has theorized how routine health-related behaviours - such as eating habits, alcohol consumption, or help-seeking - are imbued with gendered meanings and serve as gendered signifiers (Courtenay 2000; Galdas et al. 2005; Lyons 2009). From this gender and health perspective, men's greater engagement with physical activity can be understood as stemming from societal masculine ideals of physical strength and prowess (see Schippers 2007). In Western settings, some of men's relatively poorer health outcomes have been attributed to gendered patterns of riskier health behaviours among men as compared with women (Courtenay 2000; Lyons 2009). In this regard, physical activity is somewhat of a gender outlier, challenging the gendered bifurcation of men's risk-taking (healthdamaging) and women's care-taking (health-promoting) behaviour. Men are consistently more active than women across a variety of indicators and countries (Livingstone et al. 2001; Hallal et al. 2012; Lee et al. 2012).

Qualitative differences in how women and men practice physical activity may factor into this gender gap. Women are less likely to engage in vigorous levels of activity as compared with men (Grzywacz and Marks 2001; Livingstone et al. 2001; Colley et al. 2011; Hallal et al. 2012) - and this is where the greatest health benefits stand to be gained (Tremblay et al. 2011). Sallis et al. (1992) found that social factors, such as friends and family support, are important for women's vigorous activity adoption but not for men's; whereas, environmental factors, such as neighbourhood environment, predicted men's adoption but not women's. These findings suggest that social and material features of exercise environments and places may have differential gender effects on participation and activity selection. This idea is supported by Pascual et al. (2009) in their study of the influences of provincial socioeconomic status and facility availability on physical activity uptake in Spain. Focusing on one non-facility activity type (jogging) and two 
facility-based types (swimming, gym use), they found that number of facilities does not impact swimming or gym use, but area level socioeconomic status is related to women's gym use.

Gendered work and family roles may set up differential opportunities for men's and women's participation in physical activity. In a four-year follow up study of Australian women, Brown and Trost (2003) found that women who married, had children, or began paid employment since baseline are more likely to be physically inactive than women who do not experience these life events. Relatedly, in a cross-national comparison of gender differences in leisure time across Australia, the United States (US), France, Italy, and Denmark, Craig and Mullan (2013) found that the distribution of quantity and quality of leisure time consistently favoured fathers over mothers. This evidence suggests that gendered social roles and expectations underpin gender gaps in physical activity.

Men and women may also be socialized to participate in different activities. In Gilmour's analysis of the 2005 Canadian Community Health Survey, estimates for all but one of the 22 activities reported are significantly different for women and men. Perceptions about the gender appropriateness of sports and exercise can play a role in gender-typing activities. For example, a study of US university students' views on ice hockey found that when women perceive a sport to be masculine, they are less likely to view themselves as competent in it (Solmon et al. 2003). Several researchers point to a lack of attention to specific activity types in physical activity research as clouding our understanding of the gendered dimensions of physical activity (Livingstone et al. 2001; Pascual et al. 2009). Observing a concentration of women's physical activity in household tasks, Livingstone et al. (2001), in their Irish study, argued that physical activity measures that obscure gender variations in activity type may misreport and underestimate women's participation. Pascual et al. (2009) echoed this, noting that physical activity is usually operationalized as a generic derived variable, insensitive to the particularities of specific physical activities. They posit that the specificities of activity type are important for theorizing the links between physical activity and place.

There is some evidence that socioeconomic factors may play a role in the relationship between physical activity and gender. In the Spanish study by Pascual et al. (2009), for example, area level socioeconomic status is associated with women's gym use, but not men's. They also found a graded association between individual level socioeconomic status and frequency of jogging, swimming, and gym attendance. Eyler (2003), studying physical activity among rural Midwestern white women in the US, found that higher income and employment are associated with meeting physical activity recommendations. In line with this, Grzywacz and Marks (2001), using a large national survey in the US, found that high income increased women's chances of vigorous physical activity, but that income had no effect for men. In addition, education had opposite effects for men and women, with more education linked to the sharpest declines in exercise with age for women, and low education linked to the steepest decline with age for men. Socioeconomic factors can thus have gender differential effects. This might explain why a systematic review of 33 studies on socioeconomic position and physical activity found mixed evidence in relation to gender and no confirmation of social gradients in physical activity at the area or individual level; however, the review generally supported the view that people at the top end of the socioeconomic ladder fare better than those at the bottom (Gidlow et al. 2006). For both men and women, physical activity generally declines with age (Livingstone et al. 2001; Gidlow et al. 2006; Gilmour 2007; Hallal et al. 2012). While there is substantial evidence about some of the compositional factors (characteristics of individuals) that may account for gendered inequities in physical activity, knowledge about which aspects of context (features of environments) may be implicated is more limited (Macintyre et al. 2002).

Curiously, geographical research on physical activity has arguably ignored gender, for the most part subscribing to ecological approaches that emphasize the neighbourhood built environment (Andrews et al. 2012; Colls and Evans 2013). Recently this work has come under critique for environmental determinism (Colls and Evans 2013), inattention to human agency and subjective experiences (Blacksher and Lovasi 2012), and overemphasis on some types of physical activities, such as walking (Andrews et al. 2012). This paper advances such critical and feminist directions by explicitly focusing on the gendered dimensions of geographies of physical activity.

Limited research has demonstrated that geography matters for the magnitude and direction of gender differences in physical activity. Van Tuyckom et al. (2010) undertook a comparative study of gender differences in regular sports participation in 25 European states. In 12 countries, more men than women participate in regular sport; in four countries this is completely inverted with a higher portion of women participating; and in the remaining countries there is no significant gender difference. Stratification by age sub-group revealed further gender differences between places, including age-specific gender differences in countries where no 
overall gender difference is detected. Place-based gendered social hierarchies and inequities may be implicated in these geographical gender differences. In a subsequent study, comparing 27 European countries, Van Tuyckom et al. (2012) found that country level gender equality directly affected gender differences in leisure time physical inactivity; differences disappeared in the most gender-equal places. They conclude that gender differences in physical activity are a social phenomenon, requiring interventions in social structures rather than at the individual level. At a more micro scale, Rind and Jones (2011) examined recreational physical activity across small area districts in England. While broad geographical patterns are similar by gender, the districts with the highest and lowest rates of physical activity are different for men and for women. This points to the potential importance of even more fine-grained geography for detecting gender differences in physical activity. Our concern in this paper is with gendered disparities in physical activity participation both within and between places.

\section{Methods}

Data

The CCHS is a cross-sectional survey that collects information on health status, health care utilization, and health determinants for a large representative sample $(n=131,498)$ of the Canadian population 12 years and older (Statistics Canada 2013a). Data are provided at the health region (small health administrative units), province and territory, and national levels (Statistics Canada 2013a). Excluding groups such as people living on reserves, persons in institutions, and the military, the survey provides an estimated 98 percent coverage of the defined population (Statistics Canada 2013a). In the analysis that follows, the data are drawn from the 2012 CCHS public use microdata files.

\section{Geographic variables}

To consider scalar variability, we included all three levels of geography available in the CCHS. Health region is used as a proxy for city because of the close correspondence between health region and central city boundaries for some of the largest metropolitan areas. At the city level, we included only Canada's three largest cities (Montreal, Toronto, and Vancouver) in order to examine relatively comparable city centres in contrast to the larger metropolitan agglomerations that might include suburban and even rural sub-populations. The urban focus also enables exclusion of the potentially intersecting effects of rural or suburban environments on gender and physical activity (Parks et al. 2003). Accordingly, the provincial sample is limited to the three provinces of the selected cities. The comparisons are thus at the city, province, and country scales.

\section{Physical activity variables}

Three different measures of physical activities are analyzed. First, we included one measure of levels of physical activity in order to test for gender differences in overall physical activity engagement. For this, we used the Physical Activity Index, a derived variable that categorizes people as 'active,' 'moderately active,' and 'inactive' in leisure time according to total daily energy expenditure ( $\mathrm{kcal} / \mathrm{kg} /$ day) (Statistics Canada 2013b). We limited this variable to a combination of the 'moderately active' and 'active' categories, in contrast to the inactive category, because we are interested in differences in physical activity participation, not sedentary behaviour. In the remainder of the paper, we use the terms active (the combination of moderately active and active) in contrast to inactive. The CCHS also measured participation in 23 specific activities, from team sports such as soccer and volleyball, to individual activities like walking, jogging, or bicycling, to group activities including social dance and aerobics.

Noting the critique that composite physical activity measures may not be sensitive to gender differences in specific activities (Livingstone et al. 2001; Pascual et al. 2009), we included two different types of leisure-time physical activities that we expect to be highly gendered: weight-training and home exercises. While most internationally accepted physical activity guidelines call for aerobic and muscle strengthening activities for both women and men, women tend to fall behind men in meeting strength training recommendations (Caspersen et al. 2000; CDC 2006; Chevan 2008). Previous Canadian data have shown a significant gender difference in weight-training participation at the national level: 23.0 percent of men versus 14.3 percent of women reported participation in weight-training at least once in the past three months 
(Gilmour 2007). Conversely, we selected home exercises because research suggests that the marketing of home exercise equipment targets feminine gender ideals and the home as a feminine space (McCormack 1999). Previous national Canadian data have also shown that significantly more women than men practice home exercises (38.1\% vs. $30.5 \%$, respectively) (Gilmour 2007). The CCHS measured weight-training and home exercise participation in response to the question: "Have you done any of the following in the past 3 months?" (Statistics Canada 2013c).

\section{Socioeconomic variables}

In addition to gender, we consider age, marital status, education, and income as predictor variables in a set of logistic regression models (see below) to understand their relationship with physical activity by geographical scale. We recognize that although the CCHS survey variable is termed sex (biological characterization as male or female), this likely refers to gender (a social construct) given that respondents self-identified in the survey. We also understand health inequities to be largely socially determined and thus use the term gender in this article. We limited our analysis to adults 18 to 64 years old because this age bracket corresponds with the Canadian Physical Activity Guidelines for adults (Tremblay et al. 2011). Due to smaller samples sizes at the city level, we amalgamated the original 10 age groups in the CCHS comprising the 18-64 range into three age sub-groups: young adults (18 to 29 years); working age adults (30 to 44 years); and older adults (45 to 64 years). To account for the potential intersections of gendered family roles and responsibilities and physical activity participation (Brown and Trost 2003; Craig and Mullan 2013), we also included marital status (married/common-law or single/widowed/divorced). Income is measured as total household income from all sources. We created income sub-groups due to smaller sample sizes at the city level. We recoded the original five income categories into three: low income $(\$ 0-\$ 39,999)$; mid income $(\$ 40,000-\$ 79,999)$; and high income (\$80,000 or more). Four categories of education levels are considered (less than secondary school, secondary school graduate, some post-secondary, and post-secondary certificate).

\section{Analysis}

We first created data sub-sets for each geographic unit of analysis for the Canadian adult population (18-64 years). We then filtered the data by a physical activity variable in order to sample only those populations engaging in the selected activities. Using SPSS for Windows Version 20, we ran cross-tabulation analysis and chi-square tests for each data set to observe if there are any statistically significant gender differences by the categories of age and income (Table 1).

To understand the socioeconomic predictors of physical activity by geographical scale, we used binary logistic regression models at the national, provincial (British Columbia, Ontario and Quebec), and city (Vancouver, Toronto, and Montreal) levels (Tables 2-4). For the national level analysis, the entire population 18 to 64 years of age was used. The Physical Activity Index, weight-training, and home exercises were used as outcome variables, whereas age, gender, marital status, level of education, and level of income were used as predictor variables. Data for the three provinces of study (British Columbia, Ontario, and Quebec) were merged together; however, the province itself was used as a dummy variable in the logistic regression models so that we can understand whether there is a significant difference in physical activity by province. Similarly, data for the city level analysis (Vancouver, Toronto, and Montreal) were also merged together with the city used as a dummy variable in the logistic regression model to understand the differences in physical activity at the city level.

\section{Results}

Gender differences in physical activity participation

Descriptive statistics in Table 1 show a complex set of gender differences. Looking at the Physical Activity Index at all three geographic scales, the gender differences are ambiguous in the sense that sometimes the percentage of men is higher and sometimes the percentage of women is higher, depending on the age and income categories. However, when we examine weight-training and home exercises nationally, men are more likely to participate in weighttraining and women are more likely to participate in home exercises. The gender gap in weighttraining is greater for young age adults in comparison to working age and older adults. These 
differences hold when age and income are taken into account, with one exception for weighttraining where income attenuates the gender gap at the national scale. At the provincial level, gender differences in weight-training are significant by age group for British Columbia and Ontario, but not Quebec. There is no significant difference between men and women by income group for weight-training in all three provinces; however, a statistically significant gender difference by income group for home exercises is observed for Ontario and Quebec, but not for British Columbia. The gender gap for all three physical activities by age and income diminishes at the city level.

\section{[PLACE TABLE 1 APPROXIMATELY HERE]}

\section{Socioeconomic predictors of physical activity}

National scale. The binary logistic regression models indicate significant gender gaps for all three physical activities at the national scale (Table 2). Women are less active than men and are about 35 percent less likely than men to participate in weight-training (odds ratio: 0.648); however, women are 1.5 times more likely than men to undertake home exercises (odds ratio: 1.508). Age, education, and income are all significant predictors of participation in active leisure-time physical activity, weight-training, and home exercises. Marital status, however, is a significant predictor of active leisure time and weight-training, but not home exercises. Single, widowed, or separated/divorced individuals are 1.7 times more likely to engage in weighttraining than those who are married or in common-law relationships (odds ratio: 1.726). Older adults and working age adults are less likely to participate in weight-training and home exercises than young adults. Individuals who are secondary school graduates or have some post-secondary education are more likely to be active than those who have not completed secondary school. Individuals with higher levels of education are also more likely to participate in weight-training compared to those who have not completed secondary school. Possessing a post-secondary certificate, however, is not a significant predictor of home exercises, but having completed some secondary school or some post-secondary education is. Total annual household income is a statistically significant predictor of being active; mid and high income individuals are more likely to be active than those earning low incomes. Mid income and high income earners are also more likely to do weight-training than low income earners. Both mid and high income individuals are also more likely to do home exercises compared to their lower income counterparts. Overall, the models explain about 3, 13, and 5 percent variability in the Physical Activity Index, weight-training, and home exercises respectively (Nagelkerke $\mathrm{R}^{2}$ : 0.034, 0.127 and 0.048).

\section{[PLACE TABLE 2 APPROXIMATELY HERE]}

Provincial scale. At the provincial scale, significant gender differences in all three physical activity types persist. Women are less likely than men to undertake active physical activity in leisure time and are 38 percent less likely than men to participate in weight-training (odds ratio: 0.616 ) in all three provinces. However, women are 1.4 times more likely to engage in home exercises than men (odds ratio: 1.405). Working age adults are less likely to do weight-training and home exercises than young adults by about 62 and 41 percent respectively, and older adults are less likely to do weight-training and home exercises than young adults, by 43 and 13 percent respectively. Being single, widowed, or separated/divorced increases chances of participating in all three activity types, especially for weight-training. Level of education is a statistically significant determinant of all three types of physical activities at the provincial level. Mid and high income groups are significantly more likely to do all three types of physical activities than the low income group. For instance, earning a mid-level household income increases the likelihood of weight-training by 2.6 times and home exercises by 1.4 times than having low income. Province of residence has a significant impact on physical activity participation. Individuals living in British Columbia and Quebec are more likely to be active and are more likely to do weight-training than residents of Ontario. In general, the models explain about 4, 14, and 5 percent of the variability in the Physical Activity Index, weight-training, and home exercises respectively (Nagelkerke $\mathrm{R}^{2}: 0.042,0.140$, and 0.046 ) at the provincial level.

\section{[PLACE TABLE 3 APPROXIMATELY HERE]}

City scale. Gender differences in physical activity diminish at the city level. Only weighttraining remains significantly gendered, with women about 49 percent less likely than men to participate in weight-training in Canada's three largest cities (odds ratio: 0.511). Working age 
adults are less active than young adults, but older adults are more active than young adults at the city level except in the case of weight-training. Single, widowed, or separated/divorced individuals are more active and are more likely to do weight-training than those who are married or common-law. Secondary school graduates are more likely to do all physical activities in comparison to those who completed less than secondary school. Level of income is a significant predictor of active leisure time and weight-training, but not of home exercise participation at the city level. In general, mid and high income earners are more likely to be active than persons with low incomes. City of residence significantly predicts active leisure time physical activity and weight-training. People from Montreal are more active (1.6 times) and more likely to weighttrain (1.4 times) than people from Toronto, but there is no difference for home exercises. Residents of Vancouver are more likely to do all three physical activities than people from Toronto. Overall, the models explain about 7, 15, and 3 percent of the variability in the Physical Activity Index, weight-training, and home exercises respectively (Nagelkerke $\mathrm{R}^{2}$ : $0.067,0.148$, and 0.025$)$.

\section{[PLACE TABLE 4 APPROXIMATELY HERE]}

\section{Discussion}

Our results demonstrate that both scale and activity type matter for how gender differences in physical activity are observed in Canada. In fact, they are inseparable. By zooming in or out, or by changing the activity lens, gender gaps emerged or disappeared. Our descriptive crosstabulation results for the Physical Activity Index revealed instances across age and income subgroups that inverted our expectation that men were consistently more active than women. Overall, however, significant gender gaps in active leisure physical activity favouring men were confirmed in all three logistic regression models. When we looked at specific activities, significant gender gaps were apparent in the expected gendered directions. Our findings thus support the notion that composite measures of physical activity, or those using only select activities, may miss gender heterogeneity or provide incomplete pictures of the gendered nature of physical activity (Livingstone et al. 2001; Pascual et al. 2009). In our analysis, the significance of gender differences in physical activity generally diminished as geographic scale decreased. One exception is weight-training where a significant gender gap persisted at the city level, with women almost 50 percent less likely than men to weight-train. In addition, geography exerts an independent contextual effect on physical activity practices at both provincial and city scales. Indeed, residents of Vancouver were more active overall and more likely to engage in weight-training and home exercises than their metropolitan counterparts. This indicates that not only do scale and activity type matter for how we identify and quantify gender differences in physical activity, but place matters. Physical activity interventions in Canada need to be gendersensitive in ways that are place-specific. This begs the question as to what features of Canadian provinces and cities are implicated in these gender dimorphic patterns of physical activity, and what features have an equalizing effect.

Vancouver, for example, is colloquially known to be a 'fit' city. Indeed, our data show that Vancouverites are more active than residents of Toronto, affirming this local cultural milieu is distinct. Yet, despite faring better overall, Vancouver is not immune to a gender gap in weighttraining. Furthermore, in contrast to both Toronto and Montreal, Vancouver has a wide network of 25 city-run community fitness centres, all accessible and relatively affordable (City of Vancouver 2015). This suggests that in addition to the availability of facilities and contextual features of cities more widely, we may need to look within specific physical activity sites, such as gyms, to understand the micro-geographies that may be at play in shaping gender differences in exercise practices. Emerging research has begun to examine how men and women experience gym environments and the factors that shape their chosen activities, use of space, and aspects of their well-being in those spaces (Coen 2015). Seeing as the gender gap in weight-training in particular is one that transcends scale, we need to look at alternative points for intervention to encourage and support women in undertaking strength training.

Our analysis confirmed our suspected gender differences in activity types. Men were consistently more likely than women to participate in weight-training, and women were more likely than men to practice home exercises, except at the city level. Situating physical activity in domestic settings may reflect a strategy to align exercise within the constraints of women's gendered household and family roles. Men and fathers often remain more physically active and enjoy more flexibility with regards to leisure time physical activity (Brown and Trost 2003; Craig and Mullan 2013). Accordingly, at the national level, being single increased chances of 
being active in leisure time and weight-training, but had no effect on home exercises, although significance was detected at provincial and city scales.

Our findings mirror the results of European research by Van Tuyckom et al. (2010) that found that analysis by age sub-group revealed previously unobserved dimensions of gender difference; countries with no overall gaps had underlying gender disparities within certain age segments of the population. Future research should investigate where disparities emerge within, as well as across, socio-economically diverse groups of men and women.

Our logistic regression analyses indicate that gender along with age, marital status, education, income, and geographical scales are good predictors of physical activity in Canada. Although all the variables are statistically significant at different geographical levels, the strength of significance diminishes at smaller geographic units like cities. In general, the socioeconomic variables predict participation in weight-training better than the Physical Activity Index and home exercises.

There are, however, two main limitations to the study. First, the CCHS questions pertaining to specific activity types analyzed do not measure the frequency or intensity of the activity performed (i.e., weight-training or home exercises) — only that it was performed at least once in the three months prior to the survey. While the CCHS does permit assessment of the number of times and the number of minutes of physical activity by specific activity type, it does not make certain distinctions about the activities. For example, in the analysis of home exercises, it is not possible to make any inferences about what types of home exercises are being performed (e.g., aerobic, anaerobic, flexibility), only that they are undertaken at home. Second, this study stopped short of considering other individual variables that may be implicated in shaping gender differences in physical activity. Income, age, education, and marital status may not always nor necessarily be the most sensitive social determinants for unpacking gender differences in physical activity; there is an array of other factors, such as work and family roles (Brown and Trost 2003; Craig and Mullan 2013) or social support (Sallis et al. 1992) with known gendered effects on physical activity participation. Indeed, the interactions of social determinants may be as important in explaining gender differences - a possibility that was beyond the scope of our analysis here given that small sample sizes, especially at the city level, precluded such considerations. Individual health status and related health behaviours (e.g., gendered body modification practices such as dieting or use of supplements) could also be complicit in the gender gap. More research is needed into other social determinants that may affect gender differences in physical activity, how individual factors may intersect to shape any gendered patterns in participation, and the contributions both of individual and contextual factors in explaining gender differences across places. Quantitative analysis also cannot explain the pervasive impacts that commercialization of exercise and body image has on women's and men's views of their bodies and the transformation of them.

\section{Conclusion}

In conclusion, we have shown that both scale and activity type are important considerations in identifying and assessing gender gaps in physical activity in Canada. We sought to determine whether gender gaps in physical activity change across geographical scale. Our findings demonstrate that they do, in a diminishing fashion as scale becomes more detailed. We also confirmed that gender differences depend upon activity type. We found that active leisure time, weight-training, and home exercises are differentially gendered across places. These Canadian findings importantly suggest that in a time of increasing global concern about physical activity, interventions may need to account for localized social, cultural, political, and material factors to improve gender equity in physical activity opportunities. Future research should investigate small area variation in different physical activity types by gender in Canada and beyond to paint a more complete picture of the geographies of gender differences in physical activity. Qualitative research is also needed to understand the on-the-ground socio-cultural factors and material infrastructure that are implicated in creating gendered effects.

Given that the activities considered here were decisively gendered and take place in discrete locations (home environments versus ostensibly other fitness centre facilities), an important line of future research would be to explore the geographies of everyday fitness activities. This would provide insight into how different sites and facilities factor into men's and women's participation and present distinct barriers and opportunities. Such research would help to ground health promotion messaging and strategies in the realities of the particular locales in which they are realized. Equalizing physical activity participation on the basis of gender is an important avenue for increasing overall participation rates. Our work suggests that health 
Accepted manuscript: Coen, S. E., Subedi, R. P., \& Rosenberg, M. W. (2016). Working out across Canada: Is there a gender gap? The Canadian Geographer, 60(1), 69-81. https://doi.org/10.1111/cag.12255

promotion messaging that simply encourages individuals to be more active is not sufficiently sensitive to gender or place.

\section{Acknowledgements}

SEC acknowledges the doctoral research award (\#134844) she holds from the Canadian Institutes of Health Research (CIHR). RPS holds an Ontario Graduate Scholarship. MWR is the Tier I Canada Research Chair in Development Studies. This research was undertaken, in part, thanks to funding from the Canada Research Chairs Program.

\section{References}

Andrews, G., E. Hall, B. Evans, and R. Colls. 2012. Moving beyond walkability: On the potential of health geography. Social Science \& Medicine 75(11): 1925-1932.

Blacksher, E., and G. S. Lovasi. 2012. Place-focused physical activity research, human agency, and social justice in public health: Taking agency seriously in studies of the built environment. Health \& Place 18(2): 172-179.

Brown, W. J., and S. G. Trost. 2003. Life transitions and changing physical activity patterns in young women. American Journal of Preventive Medicine 25(2): 140-143.

Caspersen, C. J., M. A. Pereira, and K. M. Curran. 2000. Changes in physical activity patterns in the United States, by sex and cross-sectional age. Medicine and Science in Sports and Exercise 32(9): 1601-1609.

CDC (Centers for Disease Control and Prevention). 2006. Trends in strength training-United States, 1998-2004. Morbidity and Mortality Weekly Report 55(28): 769-772.

Chevan, J. 2008. Demographic determinants of participation in strength training activities among US adults. Journal of Strength and Conditioning Research 22(2): 553-558.

City of Vancouver. 2015. Fitness centres. http://vancouver.ca/parks-recreation-culture/fitnesscentres.aspx.

Coen, S. E. 2015. Placing the gym in geographies of physical activity: An exploration of men's and women's experiences working out. Paper presented at the $16^{\text {th }}$ International Medical Geography Symposium, July 6-10, in Vancouver, Canada.

Colley, R. C., D. Garriguet, I. Janssen, C. L. Craig, J. Clarke, and M. S. Tremblay. 2011. Physical activity of Canadian adults: Accelerometer results from the 2007 to 2009 Canadian health measures survey. Health Reports 22(1): 7-14.

Colls, R., and B. Evans. 2013. Making space for fat bodies? A critical account of 'the obesogenic environment'. Progress in Human Geography 37(5): 1-21.

Courtenay, W. H. 2000. Constructions of masculinity and their influence on men's well-being: A theory of gender and health. Social Science \& Medicine 50(10): 1385-1402.

Craig, L., and K. Mullan. 2013. Parental leisure time: A gender comparison in five countries. Social Politics: International Studies in Gender, State \& Society. doi: 10.1093/sp/jxt002.

Eyler, A. A. 2003. Personal, social, and environmental correlates of physical activity in rural midwestern white women. American Journal of Preventive Medicine 25(3 Suppl 1): 86-92.

Galdas, P. M., F. Cheater, and P. Marshall. 2005. Men and health help-seeking behaviour: Literature review. Journal of Advanced Nursing 49(6): 616-623.

Gidlow, C., L. H. Johnston, D. Crone, N. Ellis, and D. James. 2006. A systematic review of the relationship between socio-economic position and physical activity. Health Education Journal 65(4): 338-367.

Gilmour, H. 2007. Physically active Canadians. Health Reports 18(3): 45-65.

Grzywacz, J. G., and N. F. Marks. 2001. Social inequalities and exercise during adulthood: Toward an ecological perspective. Journal of Health and Social Behavior 42(2): 202-220.

Hallal, P. C., L. B. Andersen, F. C. Bull, R. Guthold, W. Haskell, and U. Ekelund. 2012. Global physical activity levels: Surveillance progress, pitfalls, and prospects. The Lancet 380(9838): 247-257.

Juneau, C., and L. Potvin. 2010. Trends in leisure-, transport-, and work-related physical activity in Canada 1994-2005. Preventive Medicine 51(5): 384-386.

Lee, I. M., E. J. Shiroma, F. Lobelo, P. Puska, S. N. Blair, P. T. Katzmarzyk, and Lancet Physical Activity Series Working Group. 2012. Effect of physical inactivity on major noncommunicable diseases worldwide: An analysis of burden of disease and life expectancy. Lancet 380(9838): 219-229. 
Accepted manuscript: Coen, S. E., Subedi, R. P., \& Rosenberg, M. W. (2016). Working out across Canada: Is there a gender gap? The Canadian Geographer, 60(1), 69-81. https://doi.org/10.1111/cag.12255

Livingstone, M. B. E., P. J. Robson, S. McCarthy, M. Kiely, K. Harrington, and P. Browne. 2001. Physical activity patterns in a nationally representative sample of adults in Ireland. Public Health Nutrition 4(5A): 1107-1116.

Lyons, A. C. 2009. Masculinities, femininities, behaviour and health. Social and Personality Psychology Compass 3(4): 394-412.

Macintyre, S., A. Ellaway, and S. Cummins. 2002. Place effects on health: How can we conceptualise, operationalise and measure them? Social Science \& Medicine 55(1): 125-139.

McCormack, D. 1999. Body shopping: Reconfiguring geographies of fitness. Gender, Place and Culture: A Journal of Feminist Geography 6(2): 155-177.

Parks, S., R. Housemann, and R. Brownson. 2003. Differential correlates of physical activity in urban and rural adults of various socioeconomic backgrounds in the United States. Journal of Epidemiology and Community Health 57(1): 29-35.

Pascual, C., E. Regidor, D. Martínez, M. Elisa Calle, and V. Domínguez. 2009. Socioeconomic environment, availability of sports facilities, and jogging, swimming and gym use. Health \& Place 15(2): 553-561.

Ransdell, L. B., J. M. Vener, and K. Sell. 2004. International perspectives: The influence of gender on lifetime physical activity participation. The Journal of the Royal Society for the Promotion of Health 124(1): 12-14.

Rind, E., and A. P. Jones. 2011. The geography of recreational physical activity in England. Health \& Place 17(1): 157-165.

Sallis, J. F., M. F. Hovell, and C. R. Hofstetter. 1992. Predictors of adoption and maintenance of vigorous physical activity in men and women. Preventive Medicine 21(2): 237-251.

Schippers, M. 2007. Recovering the feminine other: Masculinity, femininity, and gender hegemony. Theory and Society 36(1): 85-102.

Shields, M., M. S. Tremblay, M. Laviolette, C. L. Craig, I. Janssen, and S. C. Gorber. 2010. Fitness of Canadian adults: Results from the 2007-2009 Canadian health measures survey. Health Reports 21(1): 21-35.

Solmon, M. A., A. M. Lee, D. Belcher, L. Harrison Jr., and L. Wells. 2003. Beliefs about gender appropriateness, ability, and competence in physical activity. Journal of Teaching in Physical Education 22(3): 261-279.

Statistics Canada. 2013a. Canadian Community Health Survey (CCHS) Annual component user guide, 2012 and 2011-2012 Microdata files. Ottawa: Statistics Canada.

-. 2013b. Canadian Community Health Survey (CCHS) Annual component - public use microdata file, 2011-2012 derived variable (DV) specifications. Ottawa: Statistics Canada.

—. 2013c. CCHS 2011-2012: Data dictionary, public use microdata file - 24-month. Ottawa: Statistics Canada.

Tremblay, M. S., D. E. Warburton, I. Janssen, D. H. Paterson, A. E. Latimer, R. E. Rhodes, M. E. Kho, A. Hicks, A. G. Leblanc, L. Zehr, K. Murumet, and M Duggan. 2011. New Canadian physical activity guidelines. Applied Physiology, Nutrition, and Metabolism 36(1): $36-46$.

Van Tuyckom, C., J. Scheerder, and P. Bracke. 2010. Gender and age inequalities in regular sports participation: A cross-national study of 25 European countries. Journal of Sports Sciences 28(10): 1077-1084.

Van Tuyckom, C., S. Van de Velde, and P. Bracke. 2012. Does country-context matter? A crossnational analysis of gender and leisure time physical inactivity in Europe. The European Journal of Public Health 1-6: doi:10.1093/eurpub/cks009. 
Accepted manuscript: Coen, S. E., Subedi, R. P., \& Rosenberg, M. W. (2016). Working out across Canada: Is there a gender gap? The Canadian Geographer, 60(1), 69-81. https://doi.org/10.1111/cag.12255

Table 1. Cross tabulations analysis of gender differences in physical activities by geographical scale

\begin{tabular}{|c|c|c|c|c|c|c|c|c|c|c|c|}
\hline \multirow[t]{2}{*}{ Geography } & \multirow[t]{2}{*}{ Variable } & \multirow[t]{2}{*}{ Categories } & \multicolumn{3}{|c|}{$\begin{array}{c}\text { Physical Activity Index } \\
\text { (Active) }\end{array}$} & \multicolumn{3}{|c|}{ Weight-training (Yes) } & \multicolumn{3}{|c|}{ Home Exercises (Yes) } \\
\hline & & & $\begin{array}{c}\text { Men } \\
\%\end{array}$ & $\begin{array}{c}\text { Women } \\
\%\end{array}$ & $\begin{array}{c}\text { Pearson } \\
\chi^{2}\end{array}$ & $\underset{\%}{\text { Men }}$ & $\begin{array}{c}\text { Women } \\
\%\end{array}$ & $\begin{array}{c}\text { Pearson } \\
\chi^{2}\end{array}$ & $\underset{\%}{\text { Men }}$ & $\begin{array}{c}\text { Women } \\
\%\end{array}$ & $\begin{array}{c}\text { Pearson } \\
\chi^{2}\end{array}$ \\
\hline \multirow[t]{6}{*}{ Canada } & Age & $\begin{array}{l}\text { Age group 18- } \\
29\end{array}$ & 49.1 & 50.9 & $31.52 * * *$ & 60.2 & 39.8 & $61.55 * * *$ & 42.2 & 57.8 & $22.43 * * *$ \\
\hline & & $\begin{array}{l}\text { Age group 30- } \\
44\end{array}$ & 46.3 & 53.7 & & 52.8 & 47.2 & & 39.7 & 61.3 & \\
\hline & & $\begin{array}{l}\text { Age group 45- } \\
64\end{array}$ & 44.3 & 55.7 & & 49.8 & 50.2 & & 37.6 & 62.4 & \\
\hline & Income & $\$ 0$ to 39,999 & 41.3 & 58.7 & & 54.0 & 46.0 & & 33.9 & 66.1 & \\
\hline & & $\begin{array}{l}\$ 40,000 \text { to } \\
79,999\end{array}$ & 45.0 & 55.0 & $83.66 * * *$ & 54.7 & 45.3 & 0.17 & 38.0 & 68.0 & $86.53 * * *$ \\
\hline & & $\begin{array}{l}\$ 80,000 \text { or } \\
\text { more }\end{array}$ & 46.0 & 54.0 & & 54.5 & 45.5 & & 43.1 & 56.9 & \\
\hline \multirow[t]{6}{*}{$\begin{array}{l}\text { British } \\
\text { Columbia }\end{array}$} & Age & $\begin{array}{l}\text { Age group 18- } \\
29\end{array}$ & 48.0 & 52.0 & 1.01 & 58.3 & 41.7 & $10.69^{* *}$ & 41.0 & 59.0 & 0.16 \\
\hline & & $\begin{array}{l}\text { Age group 30- } \\
44\end{array}$ & 45.5 & 54.5 & & 52.7 & 47.3 & & 41.8 & 58.2 & \\
\hline & & $\begin{array}{l}\text { Age group 45- } \\
64\end{array}$ & 45.8 & 54.2 & & 46.3 & 53.7 & & 41.7 & 58.3 & \\
\hline & Income & $\$ 0$ to 39,999 & 42.0 & 58.0 & & 50.0 & 50.0 & & 39.1 & 60.9 & \\
\hline & & $\begin{array}{l}\$ 40,000 \text { to } \\
79,999\end{array}$ & 44.1 & 55.9 & $13.56 * * *$ & 52.0 & 48.0 & 0.44 & 37.7 & 62.3 & $9.12 *$ \\
\hline & & $\begin{array}{l}\$ 80,000 \text { or } \\
\text { more }\end{array}$ & 49.9 & 50.1 & & 52.8 & 47.2 & & 45.1 & 54.9 & \\
\hline \multirow[t]{6}{*}{ Ontario } & Age & $\begin{array}{l}\text { Age group 18- } \\
29\end{array}$ & 50.3 & 49.7 & $15.42 * * *$ & 59.4 & 40.6 & $13.96 * * *$ & 44.3 & 55.7 & $9.77 * *$ \\
\hline & & $\begin{array}{l}\text { Age group 30- } \\
44\end{array}$ & 45.1 & 54.9 & & 52.6 & 47.3 & & 40.8 & 59.2 & \\
\hline & & $\begin{array}{l}\text { Age group 45- } \\
64\end{array}$ & 45.1 & 54.9 & & 51.6 & 48.4 & & 39.2 & 60.8 & \\
\hline & Income & $\$ 0$ to 39,999 & 41.3 & 58.7 & & 52.7 & 47.3 & & 34.9 & 65.1 & \\
\hline & & $\begin{array}{l}\$ 40,000 \text { to } \\
79,999\end{array}$ & 44.4 & 55.6 & $37.16 * * *$ & 54.5 & 45.5 & 0.92 & 39.4 & 60.6 & $34.98 * * *$ \\
\hline & & $\begin{array}{l}\$ 80,000 \text { or } \\
\text { more }\end{array}$ & 49.9 & 50.1 & & 55.3 & 44.7 & & 44.9 & 55.1 & \\
\hline \multirow[t]{6}{*}{ Quebec } & Age & $\begin{array}{l}\text { Age group 18- } \\
29\end{array}$ & 50.9 & 49.1 & $11.07 * *$ & 63.2 & 36.8 & 4.94 & 41.2 & 58.8 & 1.96 \\
\hline & & $\begin{array}{l}\text { Age group 30- } \\
44\end{array}$ & 49.9 & 50.1 & & 55.8 & 44.2 & & 37.8 & 62.2 & \\
\hline & & $\begin{array}{l}\text { Age group 45- } \\
64\end{array}$ & 45.0 & 55.0 & & 57.7 & 42.3 & & 38.5 & 61.5 & \\
\hline & Income & $\$ 0$ to 39,999 & 42.5 & 61.5 & & 60.5 & 39.5 & & 33.5 & 66.5 & \\
\hline & & $\begin{array}{l}\$ 40,000 \text { to } \\
79,999\end{array}$ & 48.1 & 51.9 & $17.90 * * *$ & 60.3 & 39.7 & 0.48 & 39.2 & 60.8 & $14.09 * * *$ \\
\hline & & $\begin{array}{l}\$ 80,000 \text { or } \\
\text { more }\end{array}$ & 51.2 & 48.8 & & 58.3 & 41.7 & & 42.8 & 57.2 & \\
\hline \multirow[t]{6}{*}{ Vancouver } & Age & $\begin{array}{l}\text { Age group 18- } \\
29\end{array}$ & 53.5 & 46.5 & $7.35^{*}$ & 58.8 & 41.2 & 1.04 & 42.9 & 57.1 & 2.15 \\
\hline & & $\begin{array}{l}\text { Age group 30- } \\
44\end{array}$ & 36.0 & 64.0 & & 51.1 & 48.9 & & 38.2 & 61.8 & \\
\hline & & $\begin{array}{l}\text { Age group 45- } \\
64\end{array}$ & 51.8 & 48.2 & & 48.6 & 51.4 & & 49.5 & 50.5 & \\
\hline & Income & $\$ 0$ to 39,999 & 48.1 & 51.9 & & 48.6 & 51.4 & & 51.3 & 48.7 & \\
\hline & & $\begin{array}{l}\$ 40,000 \text { to } \\
79,999\end{array}$ & 48.0 & 52.0 & 0.18 & 55.0 & 45.0 & 0.43 & 41.7 & 58.3 & 2.23 \\
\hline & & $\begin{array}{l}\$ 80,000 \text { or } \\
\text { more }\end{array}$ & 45.5 & 54.5 & & 55.0 & 45.0 & & 40.0 & 60.0 & \\
\hline \multirow[t]{6}{*}{ Toronto } & Age & $\begin{array}{l}\text { Age group 18- } \\
29\end{array}$ & 50.3 & 49.7 & 3.98 & 61.2 & 38.8 & 1.59 & 43.7 & 56.3 & 1.77 \\
\hline & & $\begin{array}{l}\text { Age group 30- } \\
44\end{array}$ & 40.4 & 59.6 & & 51.7 & 48.3 & & 42.3 & 57.7 & \\
\hline & & $\begin{array}{l}\text { Age group 45- } \\
64\end{array}$ & 42.1 & 57.9 & & 56.6 & 43.4 & & 36.8 & 63.2 & \\
\hline & Income & $\$ 0$ to 39,999 & 34.5 & 65.5 & & 59.2 & 40.8 & & 32.6 & 67.4 & \\
\hline & & $\begin{array}{l}\$ 40,000 \text { to } \\
79,999\end{array}$ & 45 & 55 & $6.98 *$ & 57.9 & 42.1 & 0.40 & 42.2 & 57.8 & 5.24 \\
\hline & & $\begin{array}{l}\$ 80,000 \text { or } \\
\text { more }\end{array}$ & 47.8 & 52.2 & & 54.5 & 45.5 & & 45.0 & 55.0 & \\
\hline \multirow[t]{6}{*}{ Montreal } & Age & $\begin{array}{l}\text { Age group 18- } \\
29\end{array}$ & 51.1 & 48.9 & 0.79 & 57.9 & 42.1 & 0.59 & 45.1 & 54.9 & 0.43 \\
\hline & & $\begin{array}{l}\text { Age group 30- } \\
44\end{array}$ & 46.1 & 53.9 & & 58.0 & 42.0 & & 40.9 & 59.1 & \\
\hline & & $\begin{array}{l}\text { Age group 45- } \\
64\end{array}$ & 47.4 & 52.6 & & 64.2 & 35.8 & & 44.1 & 55.9 & \\
\hline & Income & $\$ 0$ to 39,999 & 53.0 & 47.0 & & 70.0 & 30.0 & & 45.9 & 54.1 & \\
\hline & & $\begin{array}{l}\$ 40,000 \text { to } \\
79,999\end{array}$ & 43.9 & 56.1 & 3.15 & 57.4 & 42.6 & 4.18 & 44.4 & 55.6 & 1.25 \\
\hline & & $\begin{array}{l}\$ 80,000 \text { or } \\
\text { more }\end{array}$ & 46.7 & 53.3 & & 52.8 & 47.2 & & 38.8 & 61.2 & \\
\hline
\end{tabular}


Table 2. Socioeconomic predictors of physical activities across Canada

Predictor Variables and

Reference Category

Physical Activity Index

(Active/Inactive)

Weight-training (Yes/No)

Home Exercises (Yes/No)

$\beta \quad$ Odds ratio

$\beta$

Odds ratio

$\beta-0$ Odds ratio

Women

0.957

$-0.434 * * *$

0.648

$0.411^{* * * *}$

1.508

Working age adults (30-44)

Older adults (45-64)

Young adults (18-29)

$-0.314 * * * \quad 0.730$

$0.008 \quad 1.008$

$-1.037 * * *$

0.354

$-0.571 * * *$

0.565

oung adults (18-29)

$0.155^{* * *} \quad 1.168$

$0.546 * * *$

1.726

$-0.219 * * * \quad 0.804$

Single/widow/separated/

Married/Common Law

$0.533+4 * 4=1.704$

Less than sec. school

$0.533 * * * \quad 1.704$

$0.889 * * * \quad 2.433$

$0.530 * * *$

1.048

\section{Level of education}

Sec. school graduate

Some post-secondary

Post-secondary certificate

Less than sec. school

Less than sec. school

$0.148^{* * *}$

1.159
1.072

$0.361 * * *$

1.435

Total household income

$\$ 40,000$ to 79,999

\$ 0 to 39,999

0.070

$0.136^{* *}$

1.146

0.055

1.185
1.056

$\$ 80,000$ or more

$\$ 0$ to 39,999

$0.483^{* * *}$

1.621

$0.341 * * *$

1.621
1.407
0.592

$-0.523$

$0.382 * * *$

Constant

0.034

0.127

$\begin{array}{ll}0.138 & 1.267\end{array}$

0.048 
Table 3. Socioeconomic predictors of physical activities by province of residence

\begin{tabular}{|c|c|c|c|c|c|c|c|}
\hline \multirow[t]{2}{*}{$\begin{array}{c}\text { Predictor Variables and } \\
\text { Categories }\end{array}$} & \multirow[t]{2}{*}{ Reference Category } & \multicolumn{2}{|c|}{$\begin{array}{l}\text { Physical Activity Index } \\
\text { (Active/Inactive) }\end{array}$} & \multicolumn{2}{|c|}{$\begin{array}{l}\text { Weight-training } \\
\text { (Yes/No) }\end{array}$} & \multicolumn{2}{|c|}{ Home Exercises (Yes/No) } \\
\hline & & $\beta$ & Odds ratio & $\beta$ & Odds ratio & $\beta$ & Odds ratio \\
\hline Women & Men & $-0.095 * * *$ & 0.909 & $-0.484 * * *$ & 0.616 & $0.340 * * *$ & 1.405 \\
\hline \multicolumn{6}{|l|}{ Age } & & \\
\hline Working age adults (30-44) & Young adults (18-29) & $-0.272 * * *$ & 0.762 & $-1.111^{* * *}$ & 0.329 & $-0.532 * * *$ & 0.587 \\
\hline Dlder adults (45-64) & Young adults (18-29) & $0.061 *$ & 1.063 & $-0.566 * * *$ & 0.568 & $-0.173 * * *$ & 0.841 \\
\hline Single/widow/separated/ & Married/Common-law & $0.148 * * *$ & 1.159 & $0.517 * * *$ & 1.676 & $0.123 * * *$ & 1.131 \\
\hline \multicolumn{8}{|l|}{ livorced } \\
\hline \multicolumn{8}{|l|}{ Cevel of education } \\
\hline Sec. school graduate & Less than sec. school & $0.528 * * *$ & 1.695 & $0.814 * * *$ & 2.257 & $0.465 * * *$ & 1.592 \\
\hline Some post-secondary & Less than sec. school & $0.130 * * *$ & 1.139 & $0.401 * * *$ & 1.494 & $0.170 * * *$ & 1.186 \\
\hline ost-secondary certificate & Less than sec. school & 0.081 & 1.085 & 0.029 & 1.029 & 0.045 & 1.046 \\
\hline \multicolumn{8}{|l|}{ Total household income } \\
\hline 40,000 to 79,999 & $\$ 0$ to 39,999 & $0.519 * * *$ & 1.680 & $0.958 * * *$ & 2.607 & $0.346^{* * *}$ & 1.414 \\
\hline 80,000 or more & $\$ 0$ to 39,999 & $0.347 * * *$ & 1.414 & $0.545^{* * *}$ & 1.724 & $0.193 * * *$ & 1.212 \\
\hline \multicolumn{8}{|l|}{ Province of Residence } \\
\hline Quebec & Ontario & $0.265^{* * *}$ & 1.303 & $0.212 * * *$ & 1.236 & 0.050 & 1.051 \\
\hline British Columbia & Ontario & $0.483^{* * *}$ & 1.622 & $0.654 * * *$ & 1.923 & $0.382 * * *$ & 1.465 \\
\hline Constant & & -0.821 & 0.440 & 1.013 & 2.755 & 0.051 & 1.052 \\
\hline Nagelkerke $\mathbf{R}^{2}$ & & \multicolumn{2}{|c|}{0.042} & \multicolumn{2}{|c|}{0.140} & \multicolumn{2}{|c|}{0.046} \\
\hline
\end{tabular}

Note: $* p<0.5 ; * * p<0.1 ; * * *<<0.001$ 
Table 4. Socioeconomic predictors of physical activities by city of residence

\begin{tabular}{|c|c|c|c|c|c|c|c|}
\hline \multirow[t]{2}{*}{$\begin{array}{c}\text { Predictor Variables and } \\
\text { Categories }\end{array}$} & \multirow[t]{2}{*}{ Reference Category } & \multicolumn{2}{|c|}{$\begin{array}{l}\text { Physical Activity Index } \\
\text { (Active/Inactive) }\end{array}$} & \multicolumn{2}{|c|}{$\begin{array}{l}\text { Weight-training } \\
\text { (Yes/No) }\end{array}$} & \multicolumn{2}{|c|}{ Home Exercises (Yes/No) } \\
\hline & & $\beta$ & Odds ratio & $\beta$ & Odds ratio & $\beta$ & Odds ratio \\
\hline Women & Men & -0.119 & 0.887 & $-0.672 * * *$ & 0.511 & 0.150 & 0.068 \\
\hline Norking age adults (30-44) & Young adults (18-29) & $-0.214 *$ & 0.807 & $-1.148 * * *$ & 0.317 & $-0.304 * *$ & 0.005 \\
\hline Older adults (45-64) & Young adults (18-29) & $0.233^{*}$ & 1.263 & $-0.349 * *$ & 0.706 & 0.042 & 0.658 \\
\hline Single/widow/separated/ & Married/Common-Law & $0.440 * * *$ & 1.553 & $0.526 * * *$ & 1.692 & $0.184 *$ & 0.042 \\
\hline \multicolumn{8}{|l|}{ livorced } \\
\hline \multicolumn{8}{|l|}{ Cevel of education } \\
\hline Sec. school graduate & Less than sec. school & $0.480 *$ & 1.615 & $0.713 * *$ & 2.041 & $0.433 * *$ & 0.011 \\
\hline Some post-secondary & Less than sec. school & 0.151 & 1.164 & $0.359 *$ & 1.432 & 0.212 & 0.088 \\
\hline Post-secondary certificate & Less than sec. school & 0.312 & 1.366 & 0.244 & 1.276 & 0.094 & 0.583 \\
\hline \multicolumn{8}{|l|}{ Total household income } \\
\hline 40,000 to 79,999 & $\$ 0$ to 39,999 & $0.822 * * *$ & 2.275 & $1.114 * * *$ & 3.046 & 0.178 & 0.102 \\
\hline 80,000 or more & $\$ 0$ to 39,999 & $0.557 * * *$ & 1.746 & $0.861 * * *$ & 2.366 & 0.185 & 0.066 \\
\hline \multicolumn{8}{|l|}{ City of Residence } \\
\hline Montreal & Toronto & $0.478^{* * *}$ & 1.613 & $0.396 * *$ & 1.487 & 0.179 & 0.110 \\
\hline Vancouver & Toronto & $0.464 * * *$ & 1.590 & $0.576 * * *$ & 1.778 & $0.390^{* * *}$ & 0.001 \\
\hline Constant & & -1.173 & 0.310 & $0.793 * * *$ & 2.210 & -0.031 & 0.827 \\
\hline Nagelkerke $\mathbf{R}^{2}$ & & \multicolumn{2}{|c|}{0.067} & \multicolumn{2}{|c|}{0.148} & \multicolumn{2}{|c|}{0.025} \\
\hline
\end{tabular}

Note: $* p<0.5 ; * * p<0.1 ; * * * p<0.001$ 